\title{
ESA ENFERMEDAD EN LA PIEL DE LA TIERRA QUE ES EL «HOMBRE»
}

That disease in the skin of the earth which is «man»

\section{Mónica B. Cragnolini}

Universidad de Buenos Aires, Argentina

Resumen: Así habló Zaratustra puede ser leído como un texto ontológico en el que se presentan diversos «modos de ser». El modo de «ser humano», en la figura del «último hombre» supone una transformación continua de la vida animal en beneficio de la «humanización». La cultura, como «espiritualización», implica dominar la vida animal, usufructuarla, negarla. Ese «otro modo de ser» que es el Übermensch supone otro vínculo con lo viviente, un vínculo no sacrificial que analizaremos en este artículo.

Palabras clave: animalidad - ultrahombre - sacrificio - comunidad de lo viviente

ABSTRACT: Thus spoke Zarathustra may be read as an ontological text in which different «ways of being» are present. The mode of «being human», in the figure of «the last man» implies a continuous transformation of the living animal for the sake of «humanization». The culture, understood as «spiritualization», implies to dominate the living animal, to negate it. This «other way of being» which is the Übermensch means other link with the living, a non-sacrificial link, analysed in this article.

Keywords: Animality - Overman - Sacrifice - Community of living

\section{EL HOMBRE COMO ENFERMEDAD: EL ÚLTIMO HOMBRE}

Muchas veces se ha planteado, a lo largo de la historia del pensamiento occidental, que el hombre es una enfermedad de la naturaleza: una especie de anomalía que apareció sobre la faz de la tierra para quebrar un estado de convivencia de lo viviente, instaurando, desde su marca desmesurada sobre todo lo que es, un nuevo orden (la cultura) opuesto al anterior. En la época actual, y debido al estado de devastación de la tierra como consecuencia del operar humano, es necesario volver a pensar el lugar del hombre. Cuando la biodiversidad, en lugar de ser cuidada y respetada, es usufructuada en términos de «patentes» ${ }^{1}$, se hace evidente el sello de esa enfermedad de lo «humano, demasiado humano».

1. Me refiero al modo en que las grandes potencias que, como diría Heidegger, consideran a la tierra toda como una inmensa «estación de servicio» se introducen en los lugares biodiversos del mundo, y los convierten en material disponible para sus intereses económicos. Véase, inter alia, G. C. Delgado-Ramos, Biodiversidad, desarrollo sustentable y militarización. Esquemas de saqueo en Mesoamérica, México: UNAM/Plaza y Valdés, 2004, y F. Yamin, «Biodiversity, Ethics and International Law»: International Affairs (Royal Institute of International Affairs) 71/3: Ethics, the Environment and the 
Se podría interpretar Así habló Zaratustra como una larga diatriba contra el modo de «ser humano» que se constituye a partir de esa relación de ruptura con la comunidad de lo viviente. Intentaré mostrar, entonces, cómo caracteriza Nietzsche en esta obra esa «enfermedad» que es el hombre, y las posibilidades para pensar «otros modos de ser» diferentes del existente que llamamos «humano», otros modos que permitan pensar en un ser-con más hospitalario con los vivientes no humanos.

Así habló Zaratustra podría ser considerado también como un «tratado de ontología», en la medida en que por sus páginas transitan modos de ser diversos que, por otra parte, se configuran en topografías que delinean paisajes y escenografías diferentes: la montaña, la ciudad y el mercado, el mar... En cada uno de esos paisajes habita un modo de ser diferente: el último hombre, el aventurero, el eremita, el hombre superior. Estos no son simplemente formas distintas de un mismo modo de ser, por ejemplo, del humano, sino que configuran, más que «tipos de hombres» distintos, modos diferentes de ser. Y el «humano» o más específicamente, el último hombre, es un modo de ser que se caracteriza como enfermedad: «La tierra [...] tiene una piel; y esa piel tiene enfermedades. Una de ellas se llama, por ejemplo: 'hombre'»'.

¿Por qué el hombre es una «enfermedad» de la piel de la tierra? No se trata simplemente de indicar que el «modo de ser humano» está «enfermo» ${ }^{3}$, sino que lo que aquí se señala es que ese modo de ser es una «enfermedad» de la tierra. El modo de «ser humano» se ha constituido a partir de una «ruptura» con el resto de lo viviente y de la así llamada «naturaleza»: la creación de la cultura supone un quiebre con los otros modos de ser de la vida, y una forma de vinculación con estos desde la posición mayestática del sujeto soberano, dueño y señor de todo lo viviente. En esa vinculación con el resto de lo viviente, el hombre se constituye como la enfermedad de la tierra, enfermedad que la envenena y asfixia.

Todo el parágrafo 3 del «Prólogo» de la obra es un anuncio del modo de ser de lo que va «más allá del hombre» (el Übermensch, ultrahombre), y una caracterización del modo de «ser hombre» como aquello que tiene que ser superado. En los siguientes parágrafos este modo de ser ya es caracterizado como el más despreciable, el del «último hombre». Y estos últimos hombres «tienen algo de lo que están orgullosos. ¿Cómo llaman a eso que los llena de orgullo? Cultura (Bildung) lo llaman» ${ }^{4}$. En «Del país de la cultura $»^{5}$ se señala que los hombres se encuentran

Changing International Order (julio de 1995), pp. 529-546. Me he referido a este tema en «El animal como 'capital' en la biopolítica: ambiente y biodiversidad», en E. Assalone y P. Bedin (comps.), Bios y Sociedad I: Actas de las I Jornadas Interdisciplinarias de Ética y Biopolítica, Mar del Plata: Universidad Nacional de Mar del Plata, 2012, pp. 217-222.

2. Za, «Von grossen Ereignissen», KSA IV, 168, se cita por Así habló Zaratustra, trad. A. Sánchez Pascual, Madrid: Alianza, primera reimp. de la ed. rev., 1998, p. 198.

3. La enfermedad en Nietzsche es el obstáculo que permite al hombre vivir "poniéndose a prueba» para alcanzar la «gran salud» como sobreabundancia de fuerzas creadoras. He trabajado este tema en M. B. Cragnolini, «Tiempo de la salud, tiempo de la enfermedad», en Escritos de Filosofía, Academia Nacional de Ciencias, Buenos Aires, 1999, n. ${ }^{\circ} 33-34$, pp. 109-119.

4. Za, «Vorrede», $\mathbb{S} 5$, KSA IV, 19; trad. cit., p. 40. El término traducido por Sánchez Pascual como «cultura» es Bildung, y me interesa destacar cómo en este término está presente la idea de «humanización» como «formación» del modo de ser humano, en términos de cultivo de los atributos considerados humanos en el individuo.

5. Za, «Vom Lande der Bildung», KSA IV, 153 ss.; trad. cit. pp. 182 ss. 
en medio de cincuenta espejos, que reproducen su modo de ser, modo que se describe como abigarrado y lleno de colores diferentes, con todos los signos de diferentes tiempos. A esos hombres que se consideran «reales» Zaratustra no los soporta ni vestidos con estos colores ni desnudos:

Ay, me he cansado de estos hombres, los más elevados y los mejores de todos [...] Un espanto se apoderó de mí cuando vi desnudos a estos hombres, los mejores de todos: entonces me brotaron las alas para alejarme volando hacia futuros remotos.

Hacia futuros más remotos, hacia sures más meridionales que los que artista alguno haya soñado jamás: ihacia allí donde los dioses se avergüenzan de todos los vestidos!

Mas a vosotros, prójimos y semejantes, yo os quiero ver disfrazados y bien adornados, y vanidosos, y dignos, como «los buenos y justos» ${ }^{6}$.

Ese modo de ser insoportable es el «semejante», el «prójimo», el que se considera «bueno y justo», y el que busca la proximidad del «cercano», tal como lo describe Zaratustra cuando baja por primera vez de la montaña, y se dirige a la ciudad en la que los hombres se hallan reunidos en el mercado (el ámbito de la equi-valencia y lo inter-cambiable $)^{7}$. En el mundo del mercado habita el último hombre, el que quiere todo para sí, el modo de ser «sujeto» por excelencia, caracterizado por la «propiedad» y la necesidad de apropiación de todo. El «último hombre» es una excelente ilustración del modo de ser sujeto tal como lo ha pensado la modernidad: autotélicamente erigido en su yoidad como centro de la realidad y reproducido (lo mismo de lo mismo) en esos espejos que mencionaba Zaratustra. Este modo de ser del sujeto, mayestático, soberano, autotélico, es insoportable: es la enfermedad de la piel de la tierra, y por ello Zaratustra anuncia constantemente que debe ser superado. Pero si es una enfermedad, también hay que padecerla y convalecer de ella. Por ello, la Selbstüberwindung (autosuperación de ese modo de ser) implica también una Verwindung, como indica Vattimo en relación al modo en que Heidegger ${ }^{8}$ piensa la metafísica, una "convalescencia» que, en el caso de $\mathrm{Za}$ rahustra es un modo de «llevar las cenizas a la montaña», y padecer dolorosamente lo que significa el hombre?.

Este modo de ser de lo humano, caracterizado en la figura del «último hombre», se opone al «modo amado» por Zaratustra, el que es descrito desde las dieciocho afirmaciones y declaraciones de amor («Ich liebe...») del parágrafo 4 del «Prólogo». ¿Cuál es este «modo de ser» que Zaratustra puede amar, frente a ese otro modo de ser hombre, enfermedad de la tierra, que le resulta insoportable? Lo primero que señala es que «la grandeza del hombre está en ser un puente y no

6. Za, «Von der Menschen-Klugheit», KSA IV, 186; trad. cit., p. 216.

7. J. Derrida, en Políticas de la amistad (Madrid: Trotta, 1988), señala estas características como propias de la lógica del último hombre, por oposición a la comunidad de los ultrahombres.

8. Véase G. Vattimo, «Dialéctica, diferencia y pensamiento débil», en G. Vattimo y P. A. Rovatti (eds.), El pensamiento débil, trad. de L. de Santiago, Madrid: Cátedra, 1988, pp. 18-42, y El fin de la modernidad. Nihilismo y hermenéutica en la cultura posmoderna, trad. de A. Bixio, Barcelona: Gedisa, 1990, pp. 10 ss.

9. Es importante advertir que cuando en «Del hombre superior» Zaratustra se refiere a sus supuestos discípulos, señala que estos han sufrido solo por sí mismos, pero no han sabido sufrir «por el hombre»: «iPara mí no sufrís aún bastante! Pues sufrís por vosotros, no habéis sufrido aún por el hombre» (Za, «Vom höheren Menschen», KSA IV, 359; trad. cit., p. 393). 
una meta: lo que en el hombre se puede amar es que es un tránsito (Übergang) y un ocaso (Untergang)» ${ }^{10}$.

Es decir, de esa enfermedad que es el hombre lo único soportable es que es un tránsito, nada definitivo, un camino hacia otro modo de ser diferente que, para poder transformarse, debe hundirse en su ocaso. Para eso es necesario ser un «gran despreciador», construirle la casa al ultrahombre y prepararle la tierra, el animal y la planta. Si el modo de vinculación del existente humano con la tierra, el animal y la planta ha sido el que Nietzsche caracteriza en El caminante y su sombra ${ }^{11}$ en términos del exterminio o la explotación, el ultrahombre ha de estar en otra relación con todo lo que es.

Este modo de ser amado por Zaratustra es el que no quiere la conservación de sí, el que se prodiga, el que detenta la virtud que se da. Frente al modo que le provoca náuseas, este otro modo de ser despierta el amor zarathustriano, frente a la conservación de sí del último hombre, se patentiza el amor, que es siempre «no conservador». ¿Por qué indico que el amor «no conserva»? La iconografía nos ha presentado en distintos momentos del arte a Eros como aôkos, sin casa, y también como viajero, in-quietum, a veces sin ropas, sin propiedad alguna. El amor es ese impulso erótico que no se aferra a ninguna conservación: ni de sí (ya que amar es un ejercicio de otredad que implica pérdida y desposesión), ni del otro, ni a ninguna propiedad. El modo de ser sujeto supone un aferramiento de lo propio y de lo ajeno, una necesidad de «reunión» en torno a sí para la conservación, mientras que el amor, en tanto respuesta ante un otro que es extraño y no reductible a la mismidad, implica siempre el riesgo de la desposesión, de la pérdida de sí ${ }^{12}$. Tal vez por ello Zaratustra solo puede referirse a "ese otro modo de ser» que es el Übermensch, el ultrahombre, desde estas declaraciones de amor. Y por eso el ultrahombre es el que tiene la «virtud que hace regalos», virtud que patentiza la no-conservación de sí: «da lo que no tiene», es un «alma que se prodiga».

Ese amor al ultrahombre es declarado dieciocho veces a un modo de ser que implica la ruptura con ese otro modo de ser identitario del sujeto representativo, sujeto que mide todo en términos de propiedad, equivalencia y reciprocidad: el modo de ser amado disloca la idea de intercambio. Este amor desmesurado, entonces, deconstruye toda lógica identitaria, porque no ofrece reaseguros para el modo de «ser hombre» en los términos de la equivalencia.

En el segundo tratado de Genealogía de la moral se señala que el hombre tiene que ser calculable para poder establecer la idea de deuda implícita en la noción de promesa ${ }^{13}$ : para eso es necesario que el humano sea uniforme, regular,

10. Za, «Vorrede», KSA IV, 16-17; trad. cit., p. 38. Para el tema del declinar, véase P. Wolfe, "Image and Meaning in Also sprach Zarathustra»: MLN 79/5 (diciembre de 1964), pp. 546-552. Wolfe considera que los términos untergehen (y Untergang) son cruciales para comprender las imágenes nietzscheanas en Así habló Zaratustra.

11. MA II, $\ 57$, KSA II, 577-578; Humano demasiado humano, trad. de A. Brotons Muñoz, Madrid: Akal, 1996, p. 140. En este parágrafo Nietzsche vincula el nacimiento de la moral con el modo en que tratamos a los animales, haciendo patente que la Bildung supone, como proceso de humanización, un vínculo con lo viviente animal que pasa por la utilización, el desprecio, la proyección y la aniquilación, y evidenciando la crueldad en nuestro vínculo con los animales.

12. Para este tema remito a mi artículo "Amar demasiado: hacia una pérdida de sí»: Psicoanálisis y el hospital (Buenos Aires), 11/22 (verano de 2002), pp. 122-126.

13. GM II, $\mathbb{S} 1$, KSA V, 291-292; trad. cit., pp. 65-67. 
el mismo siempre (es decir, que prime en la idea de hombre la conservación de sí). Por eso Nietzsche vincula el nacimiento de los conceptos morales de deuda y castigo con la compra y la venta: es a partir de la medición y la estimación que estos surgen. También por eso es que señala que el hombre es el «animal tasador en sí»»" comparar, medir y calcular parece ser «lo propio» del hombre, y estos verbos se trasladan a la organización de las comunidades.

\section{LA CRUELDAD HACIA LO VIVIENTE}

En la conservación de sí, el modo de ser hombre se caracteriza por la crueldad hacia todo lo viviente (en sí mismo y en los otros). ¿Por qué se produce este ejercicio de crueldad que hace del hombre una enfermedad? Genealogía de la moral permite entender por qué el modo de ser humano se configura en esta relación con la vida.

Para comprender esa relación, es necesario interpretar a la voluntad de poder (Wille zur Macht) como pluralidad de fuerzas en constante movimiento, que necesitan «densificarse» temporariamente: esa densificación «limita» el devenir, generando formas, arquitecturas, estratificaciones, instituciones. Pero la voluntad de poder es Selbstüberwindung, continuo movimiento de superación de esas formas y arquitecturas, por lo cual las formas densificadas, en el devenir, deben ser disgregadas. Cuando predomina el aspecto densificador, que detiene el movimiento de la voluntad de poder, la vida se estanca, se transforma en monotonía de lo mismo que restringe o impide la diferencia. El nihilismo decadente ${ }^{15}$ es esta monotonía de lo mismo en la que predomina la conservación. Cuando en la cuarta parte de Así habló Zaratustra el científico que estudia el cerebro de la sanguijuela con su brazo sumergido en el pantano señala que el «espíritu es la vida que se saja a sí misma en vivo», ${ }^{16}$ está haciendo alusión a esas fuerzas que limitan el movimiento de lo vital, en la medida en que esas fuerzas limitadoras «hieren» a la vida. El «espíritu», en tanto atribución de lo específicamente humano, en tanto capacidad y facultad que «forma» la cultura, se opone al movimiento de lo vital, creando estructuras que detienen, temporariamente, el devenir. Pero la limitación del devenir de las fuerzas es caracterizada en el tratado III de Genealogía de la moral como una «necesidad» (aparentemente autocontradictoria) de la vida misma. Esa limitación del movimiento de lo vital, que parece negación de la vida, se transforma en el ámbito humano en el «ideal ascético», y su caracterización permite entender la razón de la crueldad:

Tiene que ser una necesidad de primer rango la que una y otra vez hace crecer y prosperar esta especie hostil a la vida — tiene que ser, sin duda, un interés de la vida misma el que tal tipo de autocontradicción no se extinga ${ }^{17}$.

14. GM II, $\mathbb{8} 8$, KSA V, 306; trad. cit., p. 80.

15. Para la caracterización del nihilismo decadente, véase M. B. Cragnolini, Nietzsche camino $y$ demora, Buenos Aires: EUDEBA, 1998, pp. 53-83.

16. Za, «Der Blutegel», KSA IV, 312; trad. cit., p. 144.

17. GM III, $\mathbb{S} 11, K S A V, 363 ;$ La genealogía de la moral, trad. de A. Sánchez Pascual, Madrid: Alianza, ${ }^{5} 1980$, p. 137. 
En este sentido, la vida ascética es una autocontradicción porque en ella opera un resentimiento que se nutre de las fuerzas más profundas de la vida, precisamente para negarla: por ello el sacerdote ascético detesta el florecimiento fisiológico, y sus manifestaciones en la belleza, y la alegría, y prefiere el fracaso, la autoflagelación, y el autosacrificio. Lo que aquí acontece —explica Nietzsche- es que se produce «una escisión que se quiere escindida, que se goza a sí misma en ese sufrimiento ${ }^{18}$ y que se afirma en la medida en que debilita lo vital.

La vida necesita de esa negación que la hiere (porque la limita en su movimiento) pero el cultor del ideal ascético por excelencia, que para Nietzsche es el sacerdote, «goza» en esa escisión. Es decir, el ideal ascético es «una estratagema en la conservación de la vida», ${ }^{19}$ por lo tanto el sacerdote contribuye, desde este ideal de conservación, a crear mejores condiciones de vida para los hombres ${ }^{20}$ pero al mismo tiempo existe un «goce» en el dolor que supone el mantenimiento y fomento de la enfermedad. La enfermedad que es el hombre es la condición «normal» ${ }^{21}$ : por ello el sacerdote ascético conserva la enfermedad, la ampara, porque es un enfermo que vive de la enfermedad de los otros. Esto genera resentimiento contra la salud y la vida, y mecanismos para sacrificarlas. La astucia del sacerdote consiste en envenenar la vida, y en modificar la dirección del resentimiento (para que no estalle), pero siempre actúa a través de él el «instinto curativo de la vida» ${ }^{22}$. Lo que hace el ideal ascético es uniformizar: gregariza, rutiniza (instaurando la maquinaria del trabajo como olvido del dolor de la vida), disciplina, atemoriza. El sacerdote sacrifica la diversidad y la «animalidad $»^{23}$ en el hombre, siendo expresión de un «odio contra lo animal» ${ }^{24}$. Este odio se patentiza en la tortura de la corporalidad, como «lugar» del animal en el humano, generando el «animal interior ${ }^{25}$ en el hombre: una fiera que está esperando siempre la ocasión de la venganza. Y esa venganza se suele ejercer contra todo lo viviente «no espiritualizado»: la vida de los vivientes no humanos. El hombre, en la medida en que se define por sus propiedades diferenciadoras de lo animal, se convierte en el torturador de la animalidad en sí mismo y en los otros (en el cuerpo de los otros), y de los animales no humanos en general.

Cuando Nietzsche describe el nacimiento de la "mala conciencia» ${ }^{26}$ hace hincapié en el modo en el que la crueldad antes expresada en lo exterior «se vuelve hacia adentro", (interiorización) convirtiendo al hombre, a través del espíritu (o del alma), en una bestia salvaje que inhibe todos esos instintos y se tortura a sí mis-

18. Ibid.

19. Ibid.

20. GM III, $\mathbb{S} 13, K S A V, 366$; trad. cit., p. 140.

21. GM III, $\mathbb{S} 14, K S A V, 367$; trad. cit., p. 141

22. GM III, $\mathbb{1} 16, K S A V, 375$; trad. cit., p. 149.

23. GM III, $\mathbb{2} 20, K S A V, 388$; trad. cit., p. 162

24. GM III, $\mathbb{2} 28, K S A V, 412$; trad. cit., p. 185.

25. G. Agamben, en L'aperto. L'uomo e l'animale (Torino: Bollati Boringhieri, 2002), señala que es necesario replantearse la cuestión del humanismo y del hombre, en la medida en que la oposición entre la vida humana y la de los demás vivientes se da porque la vida animal se separa «en el interior del hombre». A esto alude Nietzsche con la temática del «animal interior», y podríamos considerar todo el proceso de «humanización» como esta separación en el interior del hombre, y el sacrificio infligido a esa vida animal.

26. GM II, $\mathbb{1} 16, \mathrm{KSA} V$, 321 ss.; trad. cit., pp. 95 ss. 
ma. Eso es el espíritu, esa es la mala conciencia: el hombre volviendo la crueldad contra su propio cuerpo, y considerando repugnantes «la alegría y la inocencia del animal ${ }^{27}$ presentes en él. El hombre que debe convertir su existencia en una habitualidad regular, comienza a perseguirse y a morderse a sí mismo, lanzándose contra los barrotes de su jaula, y convirtiendo su cuerpo en una cámara de torturas. De alguna manera Nietzsche está refiriéndose a lo que Derrida ha denominado la «guerra santa contra el animal» ${ }^{28}$, ese vínculo de crueldad con lo viviente que, en épocas de paz y seguridad, se torna guerra contra el animal en uno mismo.

En Así habló Zaratustra este ejercicio de crueldad contra la vida en uno mismo y en los otros se evidencia en el capítulo «Del pálido delincuente». Algo que Kafka ha descrito de manera magistral con la máquina de la colonia penitenciaria, y que en Nietzsche aparece también referido al modo en que el ejercicio de la justicia supone siempre crueldad: «Vosotros, jueces y sacrificadores, ¿̇no queréis matar hasta que el animal haya inclinado la cabeza? Mirad, el pálido delincuente ha inclinado la cabeza: en sus ojos habla el gran desprecio» ${ }^{29}$.

Kafka ha mostrado en su relato «En la colonia penitenciaria» ${ }^{30}$ el modo de vinculación con lo viviente que supone la idea de «humanización». En efecto, el proceso allí descrito, en el que el condenado, caracterizado como un animal, se halla encadenado por el cuello, las manos y los pies, enmudecido, y recibiendo en su cuerpo la escritura de la norma que ha quebrantado, mediante el operar de agujas que se hunden en su carne hasta matarlo, es el proceso de la tortura de la carne que supone el «llegar a ser humano». El condenado, caracterizado como «perro sumiso", debe soportar la tortura de su carne, la muerte y el enterramiento: la norma que «humaniza» entierra lo vital y animal para poder ejercer su poder. Ese ejercicio de la crueldad sobre el cuerpo del hombre es lo que convierte al «hombre mismo en el mejor animal doméstico del hombre ${ }^{31}$, como señala Zaratustra. Los jueces de «El pálido delincuente» también exigen sumisión del condenado, por ello, entre estos hombres enfermos de crueldad interiorizada, Zaratustra se siente un nómada:

Pero no he encontrado hogar en ningún sitio: un nómada soy yo en todas las ciudades, y una despedida junto a todas las puertas.

Ajenos me son, y una burla, los hombres del presente, hacia quienes no hace mucho me empujaba el corazón; y desterrado estoy del país de mis padres y de mis madres.

Por ello amo yo ya tan solo el país de mis hijos, el no descubierto, en el mar remoto: que lo busquen incesantemente ordeno yo a mis velas.

En mis hijos quiero reparar el ser hijo de mis padres: iy en todo futuro - este presente! ${ }^{32}$.

27. GM II, $\mathbb{S} 7$, KSA V, 302-303; trad. cit., p. 77.

28. Derrida se refiere con este sintagma, "guerra santa contra el animal», al modo en que las tres grandes religiones monoteístas no consideran «asesinato» la muerte de ese otro que es el animal, a pesar que de que son «religiones de la caridad y del amor al prójimo». Véase J. Derrida, El animal que luego estoy si(gui)endo, trad. de C. de Peretti y C. Rodríguez Marciel, Madrid: Trotta, 2008, espec. pp. 122 ss.

29. Za, «Vom bleichen Verbrecher», KSA IV, 45; trad. cit., p. 70.

30. F. Kafka, Relatos completos I, trad. de N. Mendilaharzu de Machain y J. L. Borges, Buenos Aires: Losada, 1994, pp. 131-161.

31. Za, "Von der verkleinernden Tugend», KSA IV, 214; trad. cit., p. 245.

32. Za, «Vom Lande der Bildung», KSA IV, 155; trad. cit., pp. 184-185. 
Frente al mundo de la cultura y del presente, que implica tortura habitualizada y legalizada de lo vital, Zaratustra plantea que ese modo de ser del hombre es solo un puente, un camino hacia otro modo de ser que representa una promesa. El hombre del presente, que se halla en guerra contra lo vital en sí mismo y en los otros, realiza promesas en el marco del derecho, signado por las ideas de culpa y castigo, mientras que Zaratustra piensa en otra promesa, la del ultrahombre, que no es del orden de la conservación sino del riesgo y del quizás ${ }^{33}$.

\section{EL ULTRAHOMBRE COMO PROMESA DE OTRO VÍNCULO CON LO VIVIENTE}

¿Cómo es caracterizada esta promesa que es el Übermensch, para poder entender por qué su vínculo con lo viviente ha de ser otro bien diferente al del modo de ser humano? ${ }^{34}$ Como hemos indicado, el último hombre es el pequeño propietario del mundo del mercado, que dice "Todo para mí» ${ }^{35}$. Ante este modo de ser de lo humano, el ultrahombre implica la no-propiedad, el «desasimiento» (Loslössung), desapropiado incluso de sí mismo: «No quedar adheridos a nuestro propio desasimiento» ${ }^{36}$.

Mientras que el mundo del último hombre es el mundo del mercado, de la inversión en todos los órdenes, incluso en los afectos, por lo cual este modo de ser de hombre «ama incluso al vecino y se restriega contra él: pues necesita calor ${ }^{37}$, el mundo del ultrahombre es el del don. Por eso se puede hablar de una lógica paradójica del amor en el ultrahombre, frente a la lógica de inversión capitalista del último hombre. El último hombre ama al prójimo, a los más cercanos, a los semejantes, mientras que el amor al ultrahombre (y del ultrahombre) es el amor al lejano. En esa idea del último hombre en torno a la igualdad («todos somos iguales») existe un proceso de identificación en la mismidad: frente a ese amor al próximo, Zaratustra anuncia el amor al lejano, que es el amor a la diferencia: «En nuestro amigo debemos tener nuestro mejor enemigo.... ${ }^{38}$.

Mientras que el último hombre se define por sus atributos y propiedades, la virtud del ultrahombre es la «virtud que hace regalos» ${ }^{39}$, idea que podríamos aproximar a la noción de «don». Frente a la «dación» que exige reconocimiento, el don es lo que rompe con el círculo del intercambio, por ello Zaratustra pide

33. El «quizás» (vielleicht) es el modo en que podemos pensar la «filosofía de la tensión» nietzscheana; véase mi artículo «Filosofía nietzscheana de la tensión: la re-sistencia del pensar»: Contrastes. Revista Interdisciplinar de Filosofía 5 (2000), Universidad de Málaga, pp. 225-240.

34. He caracterizado la idea del Übermensch desde el amor en M. B. Cragnolini, «Aportes para una lógica paradójica del amor o sobre por qué solo se puede dar lo que no se tiene»: Cuadernos de Ética (Buenos Aires) 27 (1999), pp. 33-45. Retomo aquí algunas ideas de este trabajo, donde interpreto el «dar lo que no se tiene» en términos de la desposesión de sí que supone el amor, en tanto irrupción de una alteridad incalculable, y «desindividualización», en el sentido de «abandono» del modo de ser sujeto (en tanto poseedor de atributos) en el amor.

35. Za, «Von der schenkenden Tugend», KSA IV, 98; trad. cit., p. 123.

36. JGB, $\mathbb{} 4, K S A V, 59$.

37. Za, «Vorrede», $\mathbb{S} 5$, KSA IV, 19; trad. cit., p. 41.

38. Za, «Vom Freunde», KSA IV, 72; trad. cit., p. 97.

39. Za, «Von der schenkenden Tugend», KSA IV, 97 ss.; trad. cit., p. 122. 
a sus discípulos que ellos mismos sean ofrendas: «Esta es vuestra sed, el llegar vosotros mismos a ser ofrendas y regalos» ${ }^{40}$.

Cuando Zaratustra desea caracterizar ese otro modo de ser que es el ultrahombre, en lugar de «definirlo», comienza siempre por amarlo y afirmarlo: «Yo amo», indica en las dieciocho declaraciones de amor al porvenir antes indicadas ${ }^{41}$. Si lo que en el hombre se puede amar es que es un tránsito y un ocaso, entonces el modo de ser humano debe «declinar» en otro modo de ser. El amor de Zaratustra es un amor que se declara repetidas veces al que puede querer su declinar (y no tiene como meta, entonces, conservarse, como los últimos hombres) y que sobrepasa la idea de intercambio en la medida en que rompe, por exceso, con el modelo de la deuda («cumple más de lo que promete») y del reconocimiento («no quiere recibir agradecimiento ni devuelve nada»). Este amor ama a aquel que quiebra la lógica del propietario (de la inversión, de la conservación, de la deuda y del reconocimiento). Por ello el ultrahombre representa la paradoja del que no dando (propiedades, atributos, dones para el intercambio) «se da», y por ello «su alma se prodiga», justamente porque no se conserva a sí mismo.

En otro lugar he utilizado el término «entre» para caracterizar lo que podríamos denominar la constitución de la subjetividad en el pensamiento nietzscheano ${ }^{42}$. Nietzsche critica el modelo de sujeto metafísico de la filosofía moderna: la figura del sujeto fundacional, representativo, básicamente cognoscente. Creo que desde esa crítica y atendiendo al operar tensionante de la voluntad de poder (tensión entre fuerzas unitivas y fuerzas disgregantes), se puede postular una idea de «entre» para comprender ese otro modo de ser prometido en el ultrahombre, «entre» que significa un sujeto des-apropiado (de «sus» atributos, de «sus» propiedades), y por tanto, no necesitado de "conservar» (ya que se encuentra atravesado por la alter-idad). De allí que su virtud sea «la virtud que hace regalos», y su amor, el amor fat $^{43}$, que ama lo que acontece, dejándolo ser.

En este sentido, frente a la crueldad del que tortura lo vital para «humanizar» (entiéndase: dominar, conquistar, usufructuar) el modo de ser (ese otro modo de ser) del ultrahombre ha de implicar otra vinculación con lo viviente «dejándolo ser». Por eso es que la cuarta parte del Zaratustra exige de los posibles hombres declinantes (los hombres superiores) un «pasaje por la animalidad» que no logran cumplir, y que merece ser explicitado ${ }^{44}$.

40. Za, KSA IV, 98; trad. cit., p. 122.

41. Za, «Vorrede», $\mathbb{S} 4$, KSA IV, 16-18; trad. cit., pp. 38-40. Las citas que se entrecomillan a continuación remiten a este parágrafo del «Prólogo».

42. Véase M. B. Cragnolini, Moradas nietzscheanas. Del sí mismo, del otro y del entre, Buenos Aires: La cebra, 2006; ed. mexicana: Moradas nietzscheanas, México DF: Universidad Autónoma Ciudad de México, 2009.

43. Para una contraposición entre la compasión (propia del último hombre) y el amor fati, véase I. Macedo, «Zaratustra, compaixâo e amor fati», en R. Dias-Sabina Vanderlei y T. Barros (orgs.), Leituras de Zaratustra, Rio de Janeiro: Maud X-Faperj, 2011, pp. 83-96.

44. Me he referido con detalle a este "pasaje por la animalidad» en «Los animales de Zaratustra: Heidegger y Nietzsche en torno a la cuestión de lo viviente animal»: Estudios Nietzsche 10 (2010), pp. 53-66. Allí explico por qué considero tan relevante la cuestión animal en la cuarta parte del Zaratustra; aquí me detendré en lo que significa dicho pasaje en el vínculo con los vivientes no humanos. 


\section{EL ULTRAHOMBRE Y LA ANIMALIDAD}

Si en Así habló Zaratustra se caracteriza el modo de ser hombre en su relación con la idea de sujeto moderno, y con los atributos de este, también se vincula de manera clara este modo de ser con la crueldad hacia lo viviente que desarrolla tan explícitamente Genealogía de la moral. En «De los predicadores de la muerte» se lee: «Ahí están los seres terribles, que llevan dentro de sí el animal de presa y no pueden elegir más que o placeres o autolaceración. E incluso sus placeres continúan siendo autolaceración ${ }^{45}$.

En este texto se está indicando el modo en que el cultor del ideal ascético se vincula con esa negación de la vida: mediante el goce en esa crueldad o el sufrimiento infligido a su propia vitalidad. Frente a esta actitud ante lo vital que, como he indicado antes, es característica del «último hombre», es necesario pensar en el modo de ser del ultrahombre y su vínculo con lo viviente. Si interpretamos las tres primeras partes de Así habló Zaratustra como una búsqueda de discípulos, hay que tener en cuenta que, luego de diversos fracasos (el cadáver del «Prólogo», los aventureros del mar) en la cuarta parte de la obra aparecen los «hombres superiores», posibles discípulos anhelados por el profeta. Y se puede sostener que ellos no son los discípulos esperados (a pesar de que saben que Dios ha muerto y asumen en sus existencias lo que significa esta pérdida) porque hay un «encuentro» que los hace huir: el encuentro con los animales, en esa figura del león riente y la bandada de palomas que aparece al fin del texto.

Si, como creo, Así habló Zaratustra es una obra de pasajes y de tránsitos ${ }^{46}$, hay un pasaje más allá de lo humano que se señala a lo largo de la obra con el continuo ir de Zaratustra a «dejar sus cenizas a la montaña», pasaje que no es solo el movimiento de la transformación en la persona del profeta sino también, de alguna manera, el movimiento del «ocaso» de Occidente y su idea de lo humano. Y si la idea de lo humano ha estado signada por esa crueldad con respecto a lo viviente antes destacada, es necesario pensar, en ese declinar, otro vínculo con la animalidad. Vínculo que de ninguna manera puede significar un retorno a un "pasado animal» (como se ha planteado en algunas interpretaciones del pensamiento nietzscheano), sino «otro modo de ser» que suponga un «ser-con» no signado por la crueldad con los vivientes no humanos.

He sostenido en otros lugares que el animal en Nietzsche debe ser pensado desde la idea de lo «extraño», es decir, la alteridad que no puede reducirse a semejanzas o diferencias con el modo de ser humano ${ }^{47}$. Mientras que para el pensamiento humanista el animal es el aspecto «instintual» de lo humano que debe ser sometido a la ley de la razón, lo «dominable» en pos de la espiritualización, en

45. Za, «Von den Predigern des Todes», KSA IV, 55; trad. cit., p. 80.

46. Desarrollo esta idea en M. B. Cragnolini, «De Bactriana y el Urmi a la montaña y el ocaso. A modo de introducción a Así habló Zaratustra»: Revista de Filosofía (Santiago de Chile: Universidad de Chile), LV-LVI (2000), pp. 39-56.

47. Remito en este sentido a M. B. Cragnolini, «Extraños devenires: una indagación en torno a la problemática de la animalidad en la filosofía nietzscheana»: Instantes y Azares. Escrituras nietzscheanas (Buenos Aires: La Cebra), VIII/8 (primavera de 2010), pp. 13-30, y «Los más extraños de los extranjeros: los animales»: Actuel Marx/Intervenciones (Santiago de Chile: Universidad Arcis) 12 ( $1^{\text {er }}$ semestre de 2012), pp. 139-145. 
la cuarta parte del Zaratustra los animales hacen su irrupción — como lo «no dominable» - frente a los humanos, que, no soportando esta irrupción, deben huir. Más allá de toda interpretación «simbólica», la escena de irrupción del león y las palomas puede ser pensada en términos de qué es lo que le acontece al humano cuando se enfrenta con el modo de ser animal.

Es cierto que se podría decir que estos hombres superiores no son «humanos» en el mismo modo de ser de los últimos hombres, ya que ellos «saben» y experimentan la muerte de Dios y sus consecuencias en diferentes ámbitos: en la ciencia, en la política, en la filosofía, en el arte, en la moral, en la religión. Es por ello que, perdido el centro fundacional de sus existencias, se dirigen a las tierras de Zaratustra. Allí se encuentra Zaratustra solo, como al inicio de la obra, acompañado de los animales (no solo el águila y la serpiente, sino también esos otros animales para los que su caverna es hospitalaria: «los animales que se arrastran, que revolotean y que saltan» $)^{48}$.

La pregunta a hacerse en esta cuarta parte de la obra es si estos hombres superiores son los anhelados por Zaratustra, los que le prepararán el camino al ultrahombre. En este sentido, hay que tener en cuenta que en «Del hombre superior» se señala: «Los más preocupados preguntan hoy: ‘Cómo se conserva el hombre?’. Pero Zaratustra se pregunta, siendo el único y el primero en hacerlo: '¿Cómo se supera el hombre?’»"${ }^{49}$.

El dilema no consiste, entonces, en la conservación, porque lo «amable» del hombre es lo que deja de ser hombre, lo que permite «otro modo de ser» diferente de lo humano. Y el hombre superior, que ha desesperado de su presente, es el que se siente incómodo con las «pequeñas virtudes» propias del «último hombre», por esto, tal vez, Zaratustra puede pensar en él como una posibilidad de tránsito hacia otro modo de ser.

Sin embargo, los hombres superiores realizan dos gestos que los alejan de la posibilidad de «prepararle el camino» al ultrahombre. En primer lugar, desesperados por la falta del fundamento divino, se arrodillan ante el asno traído por los reyes. Y justifican esta acción remitiendo a lo abstracto y contradictorio que era Dios, frente a la materialidad del asno. Es decir, plantean de algún modo la cuestión del «retorno a la animalidad». Como sabemos, los «retornos» siempre tienen un tinte romántico, y Nietzsche se separó explícitamente de los modos románticos de pensamiento en su «Ensayo de autocrítica» de $1886^{50}$, que agregó a la nueva edición de El nacimiento de la tragedia. Solo el más feo de los hombres, que puede reírse e interpretar como una parodia lo acontecido en torno a la adoración del asno, parece entender que no existen retornos posibles. Y parece entender asimismo que la vida debe ser amada, ya que Nietzsche pone en su boca la expresión del amor a la vida que pide el eterno retorno: «¿Esto era la vida? quiero decirle yo a la muerte. 'iBien! iOtra vez!'» ${ }^{51}$.

Tal vez esta sea la mejor expresión de otro modo de ser frente a la vida: mientras que el cultor del ideal ascético goza con el sufrimiento que la vida es (y ese

48. Za, «Der hässlichste Mensch», KSA IV, 331; trad. cit., p. 364.

49. Za, «Von höheren Menschen», KSA IV, 357; trad. cit., p. 390.

50. «Ensayo de autocrítica», en El nacimiento de la tragedia, OC I, Escritos de juventud, ed. dirigida por D. Sánchez Meca, trad., introds. y notas de J. Llinares, D. Sánchez Meca y L. E. de Santiago Guervós, Madrid: Tecnos, 2011, pp. 329-336.

51. Za, «Das Nachtwandler-Lied», KSA IV, 396; trad. cit., p. 429. 
goce es, como indiqué más arriba, la crueldad que se ensaña con lo viviente), el hombre más feo logra indicar otra vinculación con lo viviente desde el amor a la vida tal como es (con sus dolores, con su placeres).

Pero luego de esa fiesta, Zaratustra percibe que esos hombres superiores no pueden ser sus discípulos, y es entonces cuando se produce el segundo gesto de alejamiento de la idea del ultrahombre: llegan a la montaña el león que ríe y la bandada de palomas, que envuelven al profeta en «una nube de amor» ${ }^{52}$. Los hombres superiores despiertan, y escapan ante la vista de la escena del león, que les ruge, y de las palomas, dejando solo a Zaratustra.

\section{UNA «NUBE DE AMOR» (EINE WOLKE DER LIEBE)}

Tal vez, esta «nube de amor» entre Zaratustra y los animales esté indicando un modo de ser-con no sacrificial con lo viviente. Los hombres superiores huyen ante los animales, porque siguen siendo «humanos, demasiado humanos», es decir, incapacitados de otro vínculo con lo viviente fuera del vínculo sacrificial. En su «nube de amor» Zaratustra hace patente la comunidad con lo viviente, ese otro modo de ser-con que anuncia la llegada del ultrahombre, como modo de ser ya no humano, tal vez «posthumano», que puede vincularse con la vida de otra manera. En el discurso «Del hombre superior» Zaratustra acusa a estos hombres que van a visitarlo a su caverna de no saber reír ni danzar: tal vez debamos pensar en estos verbos para comprender otro vínculo con la vida. La risa y la danza festejan la vida, algo que esa «enfermedad en la piel de la tierra que es el hombre» no puede hacer, en la medida en que su vínculo con lo vital es siempre sacrificial, ya que está signado por la idea de «sujeto» (como «aquel que sacrifica lo vital»). El amor de Zaratustra es el amor a la desposesión, por lo tanto, a lo que des-individualiza, de-subjetiviza, a lo que irrumpe y acontece.

La «nube de amor» patentiza esta irrupción (la «incalculabilidad» del otro, que no puede ser previsto). Recordemos la bellísima escena: Zaratustra se despierta, luego de la noche en la que se celebra la fiesta del asno, noche en la que el más feo de los hombres había comprendido esto:

Gracias a este día - yo estoy por primera vez contento de haber vivido mi vida entera. [...] Merece la pena vivir en la tierra: un solo día, una sola fiesta con Zaratustra me ha enseñado a amar la tierra ${ }^{53}$.

Y Zaratustra canta la canción del «otra vez», que anuncia que todo dolor pasa, más «el placer quiere eternidad ${ }^{54}$. A la mañana siguiente, cuando despierta, les dice a sus animales que los ama, pero que aún le faltan «los hombres adecuados $»^{5}$. $\mathrm{Y}$ es entonces cuando, de improviso, se siente rodeado por el revoloteo de innumerables pájaros, que lo envuelven en una «nube de amor» y lo obligan a cerrar los ojos, y al mover sus manos para defenderse de los «cariñosos pájaros», una de

52. Ibid., p. 406; trad. cit., p. 439.

53. Za, «Das Nachtwandler-Lied», KSA IV, 396; trad. cit., p. 249.

54. Ibid., 407; trad. cit., p. 437.

55. Za, «Das Zeichen», KSA IV, 406; trad. cit., p. 436. Las citas que siguen entrecomilladas en este párrafo remiten a este capítulo. 
sus manos se posa, de manera imprevista, sobre la melena de un león que «no quería apartarse de él a causa de su amor», y que reía cada vez que una paloma se deslizaba por su nariz. Zaratustra siente «su corazón aliviado» y derrama lágrimas, que son lamidas por el león, mientras que las palomas no cesan de manifestar su amor y su alegría. Toda la escena es descrita en términos de «acontecimiento», de lo imprevisto y no calculable ni programable, porque «para tales cosas no existe en la tierra tiempo alguno».

Si pensamos ese otro modo de ser del ultrahombre en la dirección ontológica indicada al inicio, es necesario considerar un modo de ser-con lo viviente ultrahumano (es decir, diferente de todo modo de ser de lo humano, modo que aún siguen expresando los hombres superiores) que está atravesado por la alteridad de los vivientes. Y destaco el término «alteridad» para indicar que el vínculo con los vivientes (humanos y no humanos) tiene que ser pensado desde la extrañeza que el otro es, extrañeza que no se reduce a lo que puede ser asimilado y «dominado» en la propia mismidad. Por ello Zaratustra aconseja que «donde no se puede continuar amando se debe - ipasar de largo! ${ }^{56}$. El modo de ser del último hombre no puede ser amado, sino despreciado por Zaratustra, por eso abandona el mundo del mercado y de la ciudad. Pero el último hombre tampoco puede amar en el modo en que lo plantea Zaratustra, ya que solo ama lo semejante.

Y por eso también, en la medida en que lo que puede amar Zaratustra es el país de sus hijos, queda solo con animales al final de la obra, porque es el modo de ser del ultrahombre el que puede, desde la virtud que hace regalos, considerar la posibilidad del amor que respeta el carácter de extrañeza que el otro es, el otro posthumano y el otro animal.

\section{CONCLUSIÓN: OTRO MODO DE SER}

Muchas veces se plantea que la devastación de la tierra a la que asistimos (el desierto que crece $)^{57}$ es consecuencia del «mal uso» de los recursos «naturales». En esa idea de «recursos» existe una consideración de que la tierra toda está al servicio del modo de ser humano, que se enseñorea sobre la realidad en la posición del soberano, dueño de todo lo viviente. Así habló Zaratustra, en el anhelo de «otro modo de ser» diferente de lo humano, critica en la figura del último hombre ese modelo de humanidad, postulando, con el ultrahombre, la posibilidad de otro vínculo con la vida.

En «De los poetas» Zaratustra señala: «A veces encuentro también en mi palomar un animal que ha venido volando y que me es extraño, y que tiembla cuando pongo mi mano sobre él ${ }^{58}$. La vida del viviente no humano es esa extrañeza frágil, que aparece como acontecimiento, como el león y las palomas, vida que debe ser respetada en su extrañeza, y con la que hay que ser hospitalarios. Tal vez la «nube de amor» de Zaratustra con los animales sea el anuncio de que ese otro modo de ser que es el ultrahombre solo puede ser pensado desde esta vinculación no sacrificial sino «amorosa» con la vida temblorosa y frágil del otro.

56. Za, «Von Vorübergehen», KSA IV, 225; trad. cit., p. 255.

57. Za, «Unter Töchtern der Wüste», KSA IV, 380; trad. cit., p. 413.

58. Za, «Von den Dichtern», KSA IV, 163; trad. cit., p. 193. 
